Introduction: Infection is one of the most common complications of breast reconstruction. The presence of bacterial biofilm on the implant surface does not always manifest itself clinically as an infection. Still little is known about the factors that trigger the transition from a normal to a pathological state. The aim of study: To examine a specific profile of microorganisms associated with a tissue expander, and to ascertain whether the collection of intraoperative bacteriological swabs constitutes a significant predictive factor. Material and methods: A 2-centre review of outcomes of breast cancer patients who underwent immediate 2-stage expander-implant breast reconstruction between June 2020 and September 2021 was conducted. During this period, 68 replacements of expanders with implants from 56 women were performed. A bacteriological swab was taken from each expander compartment, and microbiological culture was performed. Patients' characteristics were taken into consideration.

Results: Tissue expanders were implanted from 2 to 26 months. Seven patients had an emergency expander removed due to infection or damage to the device. Out of all 56 patients evaluated, 47 had a negative and 9 had a positive culture, 1 in both breasts. The results did not correlate closely with the clinical status.

Conclusions: Bacteria colonize both clinically normal and infected expanders. It is difficult to determine the specific flora associated with the pocket after expander-based reconstruction, and taking a bacteriological swab each time as a standard does not influence the success of treatment.

Key words: breast cancer, reconstruction, expander, microbiology.

Contemp Oncol (Pozn) 2021; 25 (4): 291-294 DOI: https://doi.org/10.5114/wo.2021.112561

\section{Microbiology of breast tissue expanders}

\author{
Maja Molska ${ }^{1}$, Mateusz Wichtowski ${ }^{1}$, Dawid Murawa ${ }^{1,2}$
}

${ }^{1}$ Clinic of Surgical Oncology, Poznan University of Medical Sciences, Poznań, Poland ${ }^{2} \mathrm{General}$ and Oncological Surgery Clinic, Karol Marcinkowski University Hospital in Zielona Góra, Poland

\section{Introduction}

According to the Global Cancer Statistic 2020 report from the American Cancer Society, for the first time, female breast cancer was the most commonly diagnosed cancer in the world [1]. In recent years, the number of performed mastectomies with immediate reconstruction has been increasing. Also, we can observe a trend in patients eligible for breast-conserving treatment towards choosing mastectomy and risk-reducing contralateral mastectomy, also including immediate reconstruction [2, 3]. Nowadays, we pay more attention to psychological factors and body perception in post-mastectomy women [4]. Therefore, breast cancer patients are increasingly pursuing breast reconstruction rather than traditional oncological procedures [5]. This is due to both health and psychosocial benefits [6]. Tissue expander breast reconstruction is a commonly preferred technique, owing to its safety, lower cost, and faster recovery [7]. However, despite the perioperative antibiotic therapy, years of research, and practice, infections are one of the most prevalent complications after breast reconstruction [8, 9]. This can be influenced by various factors such as obesity, hypertension, neoadjuvant chemotherapy, axillary lymph node dissection, or wound healing complications [10]. Bacterial contamination of expanders causing the infection may lead to capsular contracture and a deterioration in the patient's condition, often resulting in a loss of the expander and hence the inability to reconstruct the breast [11]. Gram-positive bacteria were detected significantly more often compared to Gram-negative (73\% vs. 27\%) [12]. The most frequently encountered organisms responsible for the infection include Staphylococcus aureus, Staphylococcus epidermidis, and Pseudomonas aeruginosa [8, 12-14].

The purpose of this study was to examine whether there is a specific profile of microorganisms in the post-mastectomy pocket after reconstruction with a tissue expander and thus whether taking a bacteriological swab as standard when replacing the expander with an implant brings measurable results.

This could contribute to the implementation of appropriate antibiotic therapy, thereby reducing the risk of surgical site infection after the first stage of breast reconstruction.

\section{Material and methods}

A 2-centre review of outcomes of breast cancer patients from the General and Oncological Surgery Clinic of the Karol Marcinkowski University Hospital in Zielona Góra, and Surgery Department of the Heart of Jesus Hospital in Środa Wielkopolska, Poland, between June 2020 and September 2021 was conducted.

We retrospectively evaluated results of patients who underwent 2-stage breast reconstruction: a tissue expander and a permanent implant. We considered only those patients from whom we collected intraoperative swabs from the post-mastectomy pocket during the expander replacement procedure. 
Table 1. Characteristics of patients

$\begin{array}{lc}\text { Variables } & \text { Number } \\ \text { Number of patients } & 56 \\ \text { Female } & 56 \\ \text { Age in years } & 29-81 \\ \text { Comorbidities } & 23 \text { women } \\ \text { Hypertension } & 11 \\ \text { Hypothyroidism } & 5 \\ \text { Diabetes } & 1 \\ \text { Arrhythmia } & 4 \\ \text { Asthma } & 2 \\ \text { HBV } & 2 \\ \text { Osteoporosis } & 1 \\ \text { Multiple Sclerosis } & 1 \\ \text { Depression } & 1\end{array}$

Table 2. The medical treatment

$\begin{array}{lc}\text { Variables } & \text { Number } \\ \text { Unilateral mastectomy } & 44 \\ \text { Bilateral mastectomy } & 12 \\ \text { Neoadjuvant chemotherapy } & 25 \\ \text { Adjuvant chemotherapy } & 2 \\ \text { Adjuvant radiation } & 13 \\ \text { Perioperative antibiotic therapy } & 56-100 \% \\ \text { Matrix } & 18 \\ \text { Synthetic } & 16 \\ \text { ADM } & 2 \\ \text { Time from the first to the second } & 2-26 \text { months } \\ \text { stage of breast reconstruction } & \end{array}$

ADM - acellular dermal matrix

During this period, we performed 68 exchanges of an expander for a breast implant in 56 patients. We collected study variables, including the patient's age, comorbidities, history of radiation and chemotherapy, presence and type of matrices used, perioperative antibiotic therapy, complications, and the time which elapsed from the first to the second stage of reconstruction. Patients' characteristics are summarized in Table 1. The medical treatment is summarized in Table 2.

In both centres, the perioperative protocol was the same due to the same operating team. We used Biofazolin antibiotic therapy up to an hour before skin incision, and then continued twice a day until the drains were removed. The operating field was washed 3 times with antiseptic fluid (Skinsept Color) and covered in the usual manner. Before implantation, the expanders were immersed in a saline solution with metronidazole, and the wounds were washed with aqueous solution of povidone iodine (Braunol). The operators changed sterile gloves before touching the expanders. Staff in the operating room was reduced to a minimum.

Tissue expanders were implanted from 2 to 26 months. Seven of the patients had complications caused by infection or damage to the device, which was the reason for the emergency expander removal. During the exchanges, we collected bacteriological swabs from each post-mastectomy pocket and expander surface, then the microbiological culture was performed under aerobic and anaerobic conditions. The microbiological media used in the study are presented in Table 3.

\section{Results}

We took 68 swabs from 56 breast cancer patients between June 2020 and September 2021. Forty-seven of them did not experience any ailments in the entire postoperative period. Seven of them had an emergency expander removed due to medical complications. There was no significant difference in demographics or in patient management.

From all analysed patients, we had 58 negative culture results in both aerobic and anaerobic cultures. Only 9 women had a positive culture result, 1 in both breasts. Staphylococcus epidermidis was identified in the majority $(40 \%)$ of these cases. However, the results did not correlate closely with the clinical status of the patients. We obtained positive bacterial culture results in both clinically infected and uninfected expanders.

In the group of women with positive culture results, we analysed the patients in terms of risk factors for surgical site infection. Three of them underwent neoadjuvant chemotherapy, and none of them was treated with radiotherapy. During reconstruction surgery, in 6 of them, a matrix was used -5 times synthetic, 1 biological. Five women had comorbidities, mainly arterial hypertension and hypothyroidism. Both young and older women ( $>55$ ) had positive culture results, with no age group predominating. The time from the first to the second stage of reconstruction ranged from 2 to 20 months. A woman in whom bacteria grew in both breasts was a 35 -year-old patient, without any comorbidities, after neoadjuvant chemotherapy. Her breasts showed no signs of infection.

Neither comorbidities, cancer treatment, perioperative antibiotic therapy, nor postoperative complications affected the results of the cultures. The varying time during which the device stayed in the body did not change the results either.

Our findings are summarized in Table 4. The cultured bacteria are presented in Table 5 .

Table 3. The microbiological media used in the study

$\begin{array}{ll}\text { Culture for aerobic bacteria } & \text { Culture for anaerobic bacteria } \\ \text { Columbia Agar + 5\% Sheep Blood } & \text { Schaedler Anaerobe Agar } \\ \text { Columbia CNA Agar + 5\% Sheep Blood } & \text { Schaedler broth with haemin and vitamin K } \\ \text { Chromogenic UTI medium } & \\ \text { Mannitol Salt Agar } & \\ \text { Sabouraud Gentamicin Chloramphenicol Agar } & \\ \text { Brain Heart Infusion Broth } & \end{array}$




\section{Discussion}

Infections are one of the most important postoperative complication. Despite many years of experience, expander infections are statistically frequent, with the risk of having to remove the device, losing the chance for reconstruction, and postponing systemic treatment. It arguably stems from the lack of appropriate perioperative antibiotic protocols and insufficient research on bacteria causing complications. We know that some bacteria colonize expanders both with and without clinical manifestation, but still little is known about the triggers for the transition from a clinically normal to a pathological condition [15]. Another problem is that, despite clinically apparent infection, the cultures often show no growth in the specimens $[8,16]$. In an extensive retrospective review published by Viola et al. in 2016 [12], out of 3082 patients who underwent immediate breast reconstruction with a tissue expander, 378 developed infections, but only 118 of them had positive intraoperative cultures. Similar results were obtained in the study by Tong et al. [16] in which patients underwent percutaneous drainage of fluid collections after mastectomy with tissue expander-based reconstruction. In the group of 563 examined patients, 30 procedures of percutaneous drainage were performed, and microorganisms were detected in only 12 samples of fluids. Taking all these variables into account, we find it difficult to analyse the correlation between the specific type of bacteria and severe complications. However, according to other publications, well-established risk factors favouring development of infection include higher body mass index, old age (> 55 years), neoadjuvant chemotherapy, axillary lymph node dissection, hypertension, active smoking, or wound healing complications [10, 17-18]. Patients with these factors should be carefully monitored and should undergo individualized antibiotic therapy.

In our study, we sought to identify microorganisms typically associated with tissue expanders, which would help in selecting the appropriate postoperative treatment and prevent the risk of infection. Our research group consisted of approximately $84 \%$ of patients without any postoperative complications, which resulted in the vast majority of our cultures being negative both in aerobic and anaerobic conditions. In our study, we did not notice any significant factors affecting the test results. Due to the lack of a larger research group or positive bacteriological culture results, we were unable to determine a specific group of bacteria associated with expanders. It is crucial to notice, however, that the bacteria grown in our cultures belong to the saprophytic flora of the human skin, which is also confirmed by the results of studies carried out by other researchers $[8,12-14]$. Therefore, we believe that paying attention to
Table 4. Results

\begin{tabular}{lc} 
Variables & Number \\
Positive culture results & 10 \\
\hline Clinically infected expander & 3 \\
\cline { 2 - 2 } & With matrix -1 \\
\hline Clinically uninfected expander & Without matrix - \\
\cline { 2 - 2 } & With matrix -5 \\
\hline Negative culture results & Without matrix - 2 \\
\hline Clinically infected expander & 48 \\
\hline Clinically uninfected expander & 54 \\
\hline Patients with the matrix used & 18 \\
\hline Clinically infected expander & 17 \\
\hline Clinically uninfected expander &
\end{tabular}

the proper preparation of the surgical field and the utmost care for asepsis constitute important predictive factors of infections. However, the presence of bacteria on expanders without clinical manifestation requires further study to determine which factors or interactions with other bacterial species are triggers for the development of complications.

On the other hand, interesting results were presented by Monroig et al. in a paper published in 2020 [14]. They compared 2 groups of patients after tissue expander breast reconstruction. Group 1 received less than 24 hours of perioperative intravenous antibiotics and oral antibiotics after discharge, and Group 2 received less than 24 hours of intravenous antibiotics only. Group 2 demonstrated a significant increase in the number of Gram-positive bacteria compared to Group 1; however, there was no significant difference in overall virulence. The loss of the device was nearly identical. Similar conclusions can be found in research from the prospective randomized clinical trial by Phillips et al. [19]. In this case, the use of antibiotics was compared up to 24 hours after surgery or until drains were removed. Surgical site infection was diagnosed in $19.4 \%$ of patients in the 24-hour group and 22.0\% in the extended group. Therefore, it also seems that careful clinical observation is more important than taking bacteriological swabs or applying a prolonged antibiotic therapy. We should also pay attention to the fact that administration of extended prophylactic antibiotics does not reduce the overall risk of surgical site infections after expander-based breast reconstruction but may influence antibiotic resistance patterns when infections occur [20]. Consequently, an individual approach as well as vigilance of physicians in the selection of treatment are crucial.

Table 5. Cultured bacteria

Aerobic conditions
Staphylococcus epidermidis $-4 x$
Staphylococcus spp. (coagulase-negative, saprophytic flora) - 2x
Staphylococcus aureus
Micrococcus spp. (saprophytic flora)

\section{Anaerobic conditions}

Cutibacterium acnes

cutibacterium avidum 


\section{Conclusions}

Our study demonstrated that bacteria colonize both clinically normal and infected expanders. It is difficult to determine the specific flora associated with the pocket after expander-based reconstruction, and taking a bacteriological swab each time as a standard does not influence the success of treatment. Further and more thorough research on this topic is necessary.

The authors declare no conflict of interest.

\section{References}

1. Sung H, Ferlay J, Siegel RL, et al. Global Cancer Statistics 2020: GLOBOCAN estimates of incidence and mortality worldwide for 36 cancers in 185 countries. CA Cancer J Clin. 2021; 71: 209-249.

2. Jones C, Lancaster R. Evolution of operative technique for mastectomy. Surg Clin North Am 2018 ; 98: 835-844.

3. Kummerow KL, Du L, Penson DF, Shyr Y, Hooks MA. Nationwide trends in mastectomy for early-stage breast cancer. JAMA Surg 2015; 150: 9-16.

4. Izydorczyk B, Kwapniewska A, Lizinczyk S, Sitnik-Warchulska K. Psychological resilience as a protective factor for the body image in post-mastectomy women with breast cancer. Int J Environ Res Public Health 2018; 15: 1181.

5. Jonczyk MM, Jean J, Graham R, Chatterjee A. Surgical trends in breast cancer: a rise in novel operative treatment options over a 12 year analysis. Breast Cancer Res Treat 2019; 173: 267-274.

6. Dauplat J, Kwiatkowski F, Rouanet P, et al. Quality of life after mastectomy with or without immediate breast reconstruction. $\mathrm{Br}$ J Surg 2017; 104: 1197-1206.

7. Bertozzi N, Pesce M, Santi PL, Raposio E. Tissue expansion for breast reconstruction: methods and techniques. Ann Med Surg (Lond) 2017; 21: 34-44.

8. Ozturk C, Ozturk CN, Platek M, et al. Management of Expanderand Implant- Associated Infections in Breast Reconstruction. Aesthetic Plast Surg 2020; 44: 2075-2082.

9. Kraenzlin FS, Saunders H, Aliu O, et al. Classification of breast tissue expander infections: back to the basics. J Surg Oncol 2019; 120: 142-147.

10. Banuelos J, Sabbagh MD, Roh SG, et al. Infections following immediate implant-based breast reconstruction: a case control study over 11 years. Plast Reconstr Surg 2019; 144: 1270-1277.

11. Sharara SL, Saunders HM, Fabre V, et al. Infection surveillance and prevention strategies to detect and prevent postaccess breast tissue expander infections. Infect Control Hosp Epidemiol 2019; 40: 1275-1277.

12. Viola GM, Baumann DP, Mohan K, et al. Improving antimicrobial regimens for the treatment of breast tissue expander-related infections. Plast Reconstr Surg Glob Open 2016; 4: e704.

13. Klein GM, Phillips BT, Dagum AB, Bui DT, Khan SU. Infectious loss of tissue expanders in breast reconstruction: are we treating the right organisms? Ann Plast Surg 2017; 78: 149-152.

14. Monroig K, Ghosh K, Marquez JE, et al. Do postoperative prophylactic antibiotics reduce highly virulent infections: an analysis of 660 tissue expander breast reconstructions. Ann Plast Surg 2020; 85 (S1 Suppl 1): S50-S53.

15. Walker JN, Pinkner CL, Pinkner JS, Hultgren SJ, Myckatyn TM. The detection of bacteria and matrix proteins on clinically benign and pathologic implants. Plast Reconstr Surg Glob Open 2019; 7: e2037.

16. Tong RT, Kohi M, Fidelman N, et al. Clinical outcomes of percutaneous drainage of breast fluid collections after mastectomy with expander-based breast reconstruction. J Vasc Interv Radiol 2013; 24: 1369-74.

17. Ozturk CN, Ozturk C, Soucise A, et al. Expander/implant removal after breast reconstruction: analysis of risk factors and timeline. Aesthetic Plast Surg 2018; 42: 64-72.
18. Fischer JP, Nelson JA, Serletti JM, Wu LC. Peri-operative risk factors associated with early tissue expander (TE) loss following immediate breast reconstruction (IBR): a review of 9305 patients from the 2005-2010 ACS-NSQIP datasets. J Plast Reconstr Aesthet Surg 2013; 66: 1504-12.

19. Phillips BT, Fourman MS, Bishawi M, et al. Are Prophylactic postoperative antibiotics necessary for immediate breast reconstruction? Results of a prospective randomized clinical trial. J Am Coll Surg 2016; 222: 1116-1124.

20. McCullough MC, Chu CK, Duggal CS, Losken A, Carlson GW. Antibiotic prophylaxis and resistance in surgical site infection after immediate tissue expander reconstruction of the breast. Ann Plast Surg 2016; 77: 501-505.

\section{Address for correspondence}

\section{Maja Molska}

Clinic of Surgical Oncology

Poznan University of Medical Sciences

82/84 Szamarzewskiegi St.

60-101 Poznań, Poland

e-mail: majaa.molska@gmail.com

Submitted: 19.11 .2021

Accepted: 05.12 .2021 